\title{
Can Tolerance Be Grounded in Equal Respect?
}

\section{Enzo Rossi}

[Accepted for publication in European Journal of Political Theory, 2012/13. Penultimate draft, final edit pending.]

\begin{abstract}
In this paper I argue that equal respect-based accounts of the normative basis of tolerance are self-defeating, insofar as they are unable to specify the limits of tolerance in a way that is consistent with their own commitment to the equal treatment of all conceptions of the good. I show how this argument is a variant of the longstanding 'conflict of freedoms' objection to Kantian-inspired, freedom-based accounts of the justification of systems of norms. I criticise Thomas Scanlon's defence of 'pure tolerance', Anna Elisabetta Galeotti's work on the relationship between tolerance, equal respect and recognition, and Arthur Ripstein's recent response to the 'conflict of freedoms' objection. The upshot of my argument is that, while valuing tolerance for its own sake may be an appealing ideal, it is not a feasible way of grounding a system of norms. I close with a thumbnail sketch of two alternative, instrumental (i.e. nonKantian) approaches to the normative foundations of tolerance.
\end{abstract}

\section{Introductory}

0.1 An affirmative answer to my title's question is becoming increasingly common in mainstream, broadly Kantian contemporary political philosophy_arguably because of the influence of Rawls' later work, ${ }^{1}$ with its strong (if not always explicit) emphasis on the link between liberal legitimacy and mutual respect between citizens. ${ }^{2}$ In a nutshell, the by now familiar idea is to extend Rawls' insights on citizenship and reciprocity and develop them into the view that, in order to properly fulfil our duties of citizenship in a liberal democratic context, we need to move beyond a conception of tolerance as grudging accommodation of diversity, and embrace tolerance as full recognition of equal status, with special regard for previously marginalised groups. ${ }^{3}$ In this sense proponents of respect-based tolerance refer to it as 'pure tolerance': equal respect is not a value to be promoted, it is a duty towards our fellow citizens that we should fulfil regardless of outcome-oriented considerations. 
In this paper I will argue that respect-based tolerance does paint an attractive view of an ideal liberal-democratic society; yet that ideal is not viable, as a foundational normative commitment to equal respect cannot yield a consistent account of the limits of tolerance. But of course that need not be an indictment of liberal tolerance, so long as we are prepared to accept more teleological and perhaps more realistic (as opposed to moralistic) accounts of the normative foundations of liberal politics.

0.2 The paper's structure is this. In the first section I provide a working account of the structure of the respect-based view of tolerance, identifying the main arguments that support it. In the following two sections I engage directly with that view. In section 1 I present Scanlon's defense of 'pure tolerance' and begin to put forward my argument against it. The third section critically discusses Anna Elisabetta Galeotti's recent work on toleration and respect, which (as I argue) can be seen as an extension of Scanlon's approach. In the fourth section I identify and discuss a further possible line of reply to my argument, namely Arthur Ripstein's recent interpretation of Kant's account of the justification of a system of norms grounded in equal freedom (which I take to be importantly similar to the idea of grounding tolerance in equal respect). In the final section I summarise my conclusions and briefly point towards two alternative, non-Kantian justifications for liberal democratic tolerance.

\section{Mapping the terrain}

1.1 Let us take a closer look at the appeal of the respect-based view of tolerance in a way that ranges over its several influential formulations. A brief overview of the main arguments for respect-based tolerance will provide our working account of the position I will criticise. We may start from Thomas Scanlon's distinction between tolerance as 'second best' and 'pure tolerance'. The former is the familiar notion of tolerance as instrumental restraint from interference with something we disapprove of: we would restrain it if the costs of doing so were not too great. ${ }^{4}$ The latter, on the other hand, is 'quite compatible with full respect for those with whom we disagree'. ${ }^{5}$ Setting aside the thorny issue of who 'we' are, ${ }^{6}$ the conceptual challenge here is that of allowing for disagreement, or perhaps even disapproval, without thereby affording a lesser status to those we tolerate. ${ }^{7}$ At any rate, while second best tolerance may be unavoidable in certain instances (racial prejudice, say), pure tolerance-respect-based tolerance, that is-is generally preferable. $^{8}$ Scanlon puts forward one main type of reason for that claim, to do with enabling 
and fostering a certain kind of relation between fellow citizens:

If tolerance is to make sense, then, we must distinguish between one's attitude toward what is advocated by one's opponents and one's attitude toward those opponents themselves: it is not that their point of view is entitled to be represented but that they (as fellow citizens, not as holders of that point of view) are entitled to be heard. ${ }^{9}$

That recognition of common (full) membership is deeper than the conflicts ('while respect for each other does not require us to abandon our disagreement, it does places limits on how this conflict can be pursued'), and is thus desirable because it avoids alienation from other citizens. ${ }^{10}$ We will consider in what sense this kind of civic relation is desirable in the next section.

1.2 A related argument has been advanced by Anna Elisabetta Galeotti. In what is perhaps the most comprehensive articulation and the respect-based view of tolerance in the literature, Galeotti puts forward considerations of justice in support of her theory of 'tolerance as recognition'. The idea is to eliminate the disadvantage of specific social and cultural groups by extending the notion of tolerance 'from the negative meaning of non-interference to the positive sense of acceptance and recognition'. ${ }^{11}$ So tolerance as recognition would complete the liberal project of social justice by affording equal status to all citizens by enabling the full inclusion of previously marginalised groups. Again, we will analyse this position in some detail in the next section.

1.3 A further argument for respect-based tolerance proceeds from stability. Here 'stability' should be understood in the ordinary sense of the term rather than in Rawls' technical sense of 'stability for the right reasons'. ${ }^{12}$ The thought is that, since tolerance as second-best appeals only if the cost of open, perhaps violent conflict is deemed to high, a deeper, moralised notion of tolerance has to become entrenched in order to shield civil coexistence from raw power-driven politics. However I will not discuss this sort of argument here, as it is not strictly speaking an argument for principled tolerance: it points to a supposed ${ }^{13}$ benefit of principled tolerance, but it does not itself justify tolerance purely as a matter of principle.

The arguments broadly canvassed above are largely complementary and form a coherent picture of the appeal of the respect-based view of tolerance. However they do not exhaust the issues of the conceptual viability, political achievability and feasibility of the view. ${ }^{14}$ Those issues will be the subject of the following section. 


\section{Respect and the limits of (pure) tolerance}

2.1 As anticipated, the argument from (lack of) civic alienation and the argument from justice as recognition are closely related. We could understand Galeotti's 'tolerance as recognition' as akin to Scanlon's 'pure tolerance': Galeotti's vision of a fully inclusive society is in fact one in which reciprocity is fully realised (by affording equal respect to previously disadvantaged group identities) and, therefore, there is no alienation between citizens.

For that vision to be feasible, however, a basic desideratum of any theory of tolerance must be satisfied: respect-based tolerance needs an account of the limits of tolerance consistent with the normative commitments that justify tolerance in the first place. ${ }^{15}$ In a nutshell, my contention is that such an account is not available within the confines of this broadly Kantian approach to tolerance, as a commitment to equal respect for citizens qua citizens does not allow discrimination between them-not even for the sake of promoting equality or tolerance itself. As will become clearer below, if we see equal respect-based tolerance as analogous to equal liberty-based normative principles (such as Rawls' first principle of justice), we could think of my argument as following in the tradition of what one may call the 'conflict of liberties' objections. ${ }^{16}$

Before presenting my argument it will be useful to get clearer about the sort of respect that is at stake here. Stephen Darwall famously distinguished between 'appraisal respect' and 'recognition respect': ${ }^{17}$ appraisal respect flows from a positive appreciation of certain features of the object of one's respect ('I really respect her artistic achievements'), whereas recognition respect is the sort of attitude warranted simply by others' presence in the community of moral concern—simply in virtue of their existence, one may say. ${ }^{18}$ A recognisably Kantian idea, recognition respect does not permit normative pluralism in its sphere of concern and generates categorical obligations whose substantive content, however, is not specified by the notion of recognition respect per se.

Quite clearly the notion of respect underpinning views of tolerance such as Scanlon and Galeotti's is the latter: we should respect our fellow citizens because we owe it to them qua citizens and qua persons, not because we value some specific aspect of their conception of the good or of their overall contribution to society. ${ }^{19}$ Respect-based tolerance, then, is underpinned by a certain moral outlook towards fellow citizens (whom we have a categorical duty to treat in a respectful way), and not by a quasi-aesthetic celebration of diversity (as that would be a 
hypothetical imperative, in crudely simplified Kantian terminology). In other words, respectbased tolerance aims to be a principled commitment to the intrinsic value of tolerance, and refuses to see tolerance as merely instrumental to the achievement of certain desirable outcomes.

2.2 We can now move on to review Scanlon's take on the issue of the limits of tolerance. His position is the familiar one that, roughly speaking, tolerance should not extend to the intolerant. Relatively few theorists would take issue with that position qua policy prescription; yet it is not clear whether it can be normatively justified within the terms of Scanlon's overall take on tolerance. More specifically, Scanlon maintains that we can rightfully withdraw tolerance from the intolerant in three senses:

First, is it intolerant to enforce tolerance in behavior and prevent the intolerant from acting on their beliefs? Surely not. The rights of the persecuted demand this protection, and the demand to be tolerated cannot amount to a demand to do whatever one wishes.

That is hardly controversial, but it only explains easy cases, as we tend to want to prevent rights violations even independently of considerations of tolerance. The more complex issue of whether a liberal state can indirectly not tolerate the intolerant by actively promoting tolerance reveals more about Scanlon's position:

Second, is it intolerant to espouse tolerance as an official doctrine? [...] Is it intolerant to have tolerance taught in state schools and supported in state-sponsored advertising campaigns? Surely not, and again for the same reasons. The advocacy of tolerance denies no one their rightful place in society. It grants to each person and group as much standing as they can claim while granting the same to others. ${ }^{20}$

That is a familiar argument from reciprocity: I can only claim entitlements that I am willing to grant to others. ${ }^{21}$ In this particular case, no-one can complain about the advocacy of tolerance, because - according to Scanlon-everyone wants to be tolerated by everyone else. But reciprocity arguments are open to the equally familiar charge of empty formalism. What if an intolerant group is happy with granting others a right to behave intolerantly towards its members? For instance, if such a group were dominant in a society it would have (perhaps somewhat myopic) strategic reasons to take that position. In which case the advocacy of tolerance, if justified only on the basis of pure reciprocity, appears to unfairly discriminate against that intolerant group. I take it that this sort of discrimination is distinct from lack of tolerance, about which the group is not concerned, after all; so perhaps the advocacy of tolerance is not intolerant, but it can lead to arbitrary discrimination (e.g. through the use of tax revenue) from the point of view of reciprocity. That is not to say that I do not support the advocacy of tolerance. My point is just that Scanlon's reciprocity argument lacks the resources to 
justify it, and thus appears to discriminate arbitrarily between people who happen to be tolerant and people who happen to be intolerant. ${ }^{22}$

More precisely, the problem that is beginning to emerge is this. If we ought to respect people simply because we owe it to them qua citizens or qua persons, it seems very hard to identify a criterion for non-inclusion that is compatible with our own guiding normative commitment. Any appeal to ulterior normative considerations would be arbitrary or ad hoc, or at any rate it would be incompatible with the idea of 'pure tolerance', in the sense that tolerance would be exercised for the sake of some other value. Scanlon does partly acknowledge this problem:

Finally, is it contrary to tolerance to deny the intolerant the opportunities that others have to state their views? This would seem to deny them a standing that others have. Yet to demand that we tolerate the intolerant in even this way seems to demand an attitude that is almost unattainable. If a group maintains that I and people like me simply have no place in our society, that we must leave or be eliminated, how can I regard this as a point of view among others that is equally entitled to be heard and considered in our informal (or even formal) politics? To demand this attitude seems to demand too much. ${ }^{23}$

But how can it be a problem of the demand? Recall that Scanlon says: 'tolerance involves a more attractive and appealing relation between opposing groups within a society'. ${ }^{24}$ This could sound like a teleological ideal, but let's try to make it as deontological as possible. I take it that the thought is that to tolerate in the pure sense just is to be in this relation. And to be in this relation is something we owe to our fellow citizens. But the somewhat perplexing point here is that Scanlon seems to imply that this relation is only valuable if it is reciprocal. That may make sense within some Kantian accounts of respect as part of personal morality: crudely, genuine respect for another person's rational nature may well require mutual recognition. But why would that be the case in a political context? It seems that, ceteris paribus, it would be preferable if at least one side were to respect and/or tolerate others.

So if that is not a problem of the demand as much as it is a problem of the view that cannot meet it - the demand is simply one for equal treatment. If that equal treatment is not forthcoming we may still say that this arrangement affords a form of respect for everyone that is compatible with the broader normative commitments of the liberal democratic state; but it certainly is not equal respect. In other words, respect is afforded to citizens in so far as their conception of the good is compatible with the normative commitments of a liberal polity. So, ultimately, it seems that on Scanlon's view tolerance is not grounded in the obligation to extend equal respect to citizens qua citizens, or to persons qua persons; rather, respect is instrumental and subordinate to the creation of a polity where a certain ideal of citizenship is realised, even at 
the expense of the equal treatment of citizens' conceptions of the good. Most of the normative work is done by the values and virtues instantiated by that polity, rather than by any moral reasons we may have to treat fellow citizens with respect.

Arguably this turns out to be a more teleological foundational account of tolerance than Scanlon seems to be comfortable with. Respect is not the moral foundation of tolerance; rather, tolerance based on recognition respect is simply a means to the end of realising a political ideal of citizenship. Scanlon effectively proposes to only tolerate people who are themselves committed to tolerance, because he deems a society where tolerance is safeguarded to be preferable to a less tolerant one. ${ }^{25}$ If the normative work is done by the vision of an ideal polity, then we don't have 'pure tolerance', but simply tolerance as a political tool for the realisation of a political goal. That need not be a problem per se (as I will argue in the final section), but it will be a problem for many neo-Kantian political philosophers. The appeal of the Kantian approach largely rests on its broadly neutralistic claim to transcend or at least bracket disagreements about which conception of the good should be affirmed by the liberal polity; but the problem of the limits of tolerance seems to thwart that ambition. ${ }^{26}$

\section{Tolerance, respect, and recognition}

3.1 Galeotti's take on the issue of the limits of tolerance is more sophisticated and farreaching; nonetheless I contend that it is not immune from a version of the objection I raised against Scanlon. Galeotti's answer to the question of where to draw the limits of tolerance is two-pronged. On the one hand she claims that we need to contain behaviour that threatens the newly acquired recognised identity of previously disadvantaged groups:

Once different identities have been legitimated in the public sphere by means of tolerance, their public presence still needs to be stabilized over time. Members of a minority group are still targets of prejudice, stereotyping, and discrimination, and their inclusion is thus undermined. ${ }^{27}$

Now, while that is certainly a morally commendable position, my concern here would be that we still lack a non-arbitrary and consistent (with the ideal of pure tolerance and equal respect) account of which minority groups are worthy of recognition and inclusion, and which ones should instead be contained. For instance, as a matter of fact both neo-Nazis and Romas (say) are unpopular and marginalised, yet it seems that the only arguments that are available to discriminate between those two groups are Scanlon-style arguments, i.e. arguments that rely on a somewhat teleological account of the ideal liberal polity—in this case one characterised by a high level of inclusion of previously disadvantaged minorities. The question, of course, is not 
whether we should actually discriminate between those groups, but whether we are justified in doing so on the basis of considerations of equal respect alone. In other words, while first-order views about the relative merits of including or excluding certain groups may often be uncontroversial, their second-order underpinnings may prove to be problematic, at least on the broadly Kantian view I am discussing here. Which is to say that Galeotti's move is open to the same objection I raised against Scanlon.

3.2 On the other hand, in more recent work Galeotti resourcefully draws a connection between the ideas of tolerance as recognition, liberal legitimacy, and equal respect. That move goes some way towards answering a well known objection to political liberalism. Consequently, it provides an interesting answer to the problem of how to specify the limits of respect-based tolerance. In a nutshell, the objection is that the political liberal ideal of reasonableness-which sets the boundaries of full inclusion in the liberal polity-is morally laden in such a way that it unwarrantedly discriminates in favour of citizens who hold broadly liberal convictions. ${ }^{28}$ In other words, reasonableness cannot provide a freestanding account of the limits of inclusion in the liberal polity because it is too strictly tied to substantial liberal commitments. Now Galeotti's move is to obviate to the problem of the arbitrary stipulation that only liberals are reasonable by having the idea of equal respect drive the identification of reasonableness, and thus the pool of people to whom the liberal state must be acceptable or publicly justified. That, in my reading, also provides an answer to the limits of tolerance problem, as those people are also the ones that merit inclusion via tolerance as recognition.

Galeotti's idea is that whoever advances a claim for recognition, regardless of their intentions, implicitly claims equal respect for themselves. ${ }^{29}$ This strategy overcomes certain difficulties of mainstream political liberalism in so far as it allows us to identify identity claims that are suitable for inclusion in a pluralist liberal democracy independently of a previous commitment to liberal values (such as the commitment to freedom and equality required from Rawls' reasonable citizens).

However I would simply object that it is far from clear that a commitment to equal respect is implicit in all claims for recognition. Galeotti says:

Regardless of the claimant's comprehensive doctrine, equal respect does not derive from a previous recognition of others as free and equal, and thus from reasonableness. Rather, it derives from the very form of the claim, which imposes on the claimant a recognition of the second-person authority of the recipient of the claim; otherwise we wouldn't have protest, avowals, and claims, but only power relations and violence. ${ }^{30}$ 
Yet that strikes me as a rose-tinted view of the reality of modern pluralistic politics, or indeed of politics simpliciter. History would caution against placing the burden of proof on the political liberal to prove that recognition claims are not instrumental, and thus just one of many tools of political expediency. To be sure, some groups do (explicitly or implicitly) claim equal (recognition) respect. But others do not-we may say that they claim a form of exclusive appraisal respect instead. So if we want to discriminate between those groups we are back to the objection I raised against Scanlon, and therefore, as we have to fall back on a substantive justification of the desirability of the sort of polity we envisage, tolerance becomes just a contingent means to achieving it, dictated by political happenstance. It seems, then, that Bernard Williams was right in observing that 'perhaps tolerance will prove to have been an interim value, serving a period between a past when no one has heard of it and a future in which no one will need it'. ${ }^{31}$

\section{Equal respect and equal freedom}

4.1 There is, however, an incisive Kantian reply to the 'conflict of freedoms' objection. Recently Arthur Ripstein has put it forward through an interpretation of the Doctrine of Right. The basic idea is to present equal freedom as a formal system that enables agents to pursue (but not necessarily achieve) their own purposes, rather than as a system for the distribution of a set of concrete possible courses of action. Ripstein puts it as follows:

Kant conceives of equal freedom differently. It is not a matter of people having equal amounts of some benefit $[\ldots]$ but of the respective independence of persons from each other. Such independence cannot be defined, let alone secured, if it depends on the particular purposes that different people happen to have. One person cannot be independent of the effects of choices made by other people, except by limiting the freedom of those people. Instead, a system of equal freedom is one in which each person is free to use his or her own powers, individually or cooperatively, to set his or her own purposes, and no one is allowed to compel others to use their powers in a way designed to advance or accommodate any other persons's purposes. $^{32}$

In other words, you are free to set your own purposes, but you are not entitled to actually achieve them. And of course you may set those purposes only insofar as you do not prevent others from doing the same. Now, that account may well work for systems of property and other similar entitlements (e.g. self-ownership and other rights over one's body), which are Kant's main focus: if we are prepared to accept a broadly libertarian account of the nature of rights, we may be attracted to the view that independence from other people's purposiveness rather than the enjoyment of certain benefits should be the focus on state-enforced legal restrictions on our 
behaviour. Analysing that position, at any rate, would be far beyond the scope of this paper. Our focus here is of course whether the idea of a system of norms grounded in equal freedom as independence can yield a consistent account of the limits of tolerance (themselves norms) grounded in equal respect. In that light, the attractive move for respect-based theorists of tolerance would be to define intolerance (i.e. disrespect) as the desire or the inclination to interfere with the purposiveness of others. In that way they would be able to ground restrictions of tolerance that are compatible with and fully justified within a formal system of equal respect, i.e. without appeal to values other than respect. And those restrictions would of course pick out precisely the intolerant groups that Scanlon and Galeotti wish to restrict.

4.2 That is quite a forceful reply to the argument I advanced so far; but I submit that a strong rejoinder is available to critics of respect-based (or 'pure') tolerance. In a nutshell, the thought is that freedom as independence turns freedom into a strongly procedural notion, and procedural norms are a way of disguising substantial normative commitments that go beyond those explicitly espoused by the procedure. That is a fairly familiar worry that has been expressed in various ways against various formulation of contemporary neo-Kantian liberalism. ${ }^{33}$ Bernard Williams lucidly formulated that point in way that should help us seeing the limits of the equal freedom/independence-based reply to my general objection to respect-based toleration:

"[the distinction between intentions and effects] makes a lot out of a difference of procedure, whereas what matters to a nonliberal believer is the difference of outcome [...] I doubt whether we can find an argument of principle that $[\ldots]$ could in principle explain to rational people whose deepest convictions were not in favour of individual autonomy and related values that they should think a state better that let their values decay in preference to enforcing them". ${ }^{34}$

In other words, the advocate of the respect-based view of tolerance would have to say to the intolerant person: 'It just so happens that you are inclined to interfere with the purposiveness of others. Nothing personal, but we're going to have to restrain you somehow.' So there is something to the Kantian argument, in the sense that it can ground norms (restrictions of tolerance, in this case) that are consistent with its commitment to equal treatment, at least procedurally. However, as Williams points out, the argument cannot do much beyond preaching to the converted: to those not already committed to equal respect and other related liberal values, the imposition of restrictions will still feel like unwarranted unequal treatment. To be sure, the neo-Kantian liberals may be prepared to bite that bullet; but the resulting view seems far from their general aspiration toward a maximally inclusive and consensus-driven polity. 


\section{Concluding observations}

5.1 My argument's aim was to show that respect-based, pure tolerance is not feasible: equal respect as a moral underpinning for tolerance leaves us unable to consistently specify the limits of tolerance. It seems, then, that we need to turn to instrumental defences of tolerance. It would be beyond the scope of this paper to explore the question of what sort of instrumental (as opposed to 'pure') defence of tolerance is preferable.

To conclude, however, it may be useful to point to the two most plausible candidates. We may distinguish between forms of moral substantivism (guided by teleological moral ideals) and forms of pragmatism or realism (guided by contingent, prudential considerations such as stability or compromise).$^{35}$ Both approaches are instrumental because tolerance is a tool for achieving specific outcomes, rather than something we are committed to for its own sake. There is nothing in the argument I offered here that suggests going in one direction or the other. From a broadly Kantian perspective they are both equally unprincipled ${ }^{36}$ - though, as we have seen, one may question the salience of that point: as it turns out, valuing tolerance for its own sake is not a workable normative commitment, as its implementation must rely on a teleological account of the liberal polity. In the light of my argument, then, both non-Kantian approaches are preferable to the Kantian one insofar as they can consistently and explicitly specify the limits of tolerance: quite simply, in both cases the limits of tolerance will be determined by a judgment as to what particular arrangement best promotes a particular set of values, be they moral ideals or pragmatic considerations. For instance, moral substantivism may rely on an impartial-welfarist ideal of well-being and maintain that a specific kind of tolerant polity (i.e. one with specific limits to tolerance and suitably attuned institutions and practices) is most apt at realising that ideal; or, in much the same way, it may rely on a perfectionist ideal of human flourishing and excellence. This approach has the advantage of preserving some of the intuitive appeal of a

connection between tolerance and the realisation of some moral ideal-yet it may also be conversely accused of grounding political action in controversial or unrealistic aspirations. Pragmatic or realistic substantivism, on the other hand, will likely proceed from an analysis of the social and political conditions peculiar to a given society, and conclude that a tolerant regime (again, with explicitly purpose-oriented limits to tolerance) is best suited to promoting or safeguarding a set of pragmatic values such as peaceful coexistence, stability, and the like. This approach may manage to sideline some ethical controversies and matters of feasibility, perhaps at the expense of some of its ability to guide deep political transformation. ${ }^{37}$ At any rate, the purpose of this paper has been to argue that there is no feasible alternative to an 'unprincipled' 
or 'impure' approach to toleration. Analysing the dialectic between substantivism and pragmatism will have to be the subject of further work. ${ }^{38}$ 
1 John Rawls (1996) Political Liberalism. $2^{\text {nd }}$ Ed. New York: Columbia University Press.

2 The precise connection between equal respect, reciprocity, and liberal legitimacy has recently been extensively explored and defended by Anna Elisabetta Galeotti (2010) La politica del rispetto: i fondamenti etici della democrazia. Rome and Bari: Laterza.

3 The most extensive formulation of this view can be found in Anna Elisabetta Galeotti (2002) Toleration as Recognition. Cambridge: Cambridge University Press. Other influential exponents of respectbased accounts of tolerance are Thomas Scanlon, 'The Difficulty of Tolerance', in D. Heyd (ed.) (1996) Toleration: An Elusive Virtue pp226-239. Princeton: Princeton University Press and Albert Weale (1985). Critical discussions of the view can be found in Peter Jones (2006) 'Toleration, Recognition and Identity', Journal of Political Philosophy, 14: 123-143 and Bernard Williams, 'Tolerance: An Impossible Virtue?', in D. Heyd (ed.) (1996) Toleration: An Elusive Virtue pp18-27 (cit.).

4 More precisely, there has to be a sufficient reason to override the objection component that is implicit in any tolerance relation. Typically, the reason will be prudential.

5 Scanlon, n. 3, p. 226.

6 There is of course an important issue to do with whether we think of tolerance as a virtue that individual citizens should exhibit in their public and/or private lives, as opposed to tolerance on the part of those designing institutions and/or exercising political authority more generally. In either case, tolerance does seem to presuppose a certain hierarchical relationship, in so far as to even have the option to tolerate someone we need to be in a position to not do so, if we so wish. Though of course this option, and the accompanying hierarchical relation, may well be simply hypothetical ('even if we could oppress you, we wouldn't'). As Bernard Williams notes, 'basically, tolerance is a matter of the attitudes of any group to another and does not concern only the relations of the more powerful to the less powerful'. (n.2, p. 19, emphasis added.) Williams also notes that tolerance as a practice need not be supported by the attitude of tolerance-attitudes like indifference will do.

7 In Rainer Forst (2007) 'Toleration'. Stanford Encyclopedia of Philosophy. URL: http://plato.stanford.edu/entries/tolerance/ (Accessed 4.6.2010) these two desiderata are termed the 'objection component' and the 'acceptance component' of tolerance.

8 For an overview of the historical development of the contrast between the 'hierarchical permission' and 'democratic respect' conceptions of tolerance see Rainer Forst (2010) 'Two Stories about Toleration'. RECON Online Working Papers Series 2010/15. Oslo: RECON. URL: http://ideas.repec.org/p/erp/reconx/p0071.html.

9 Scanlon, n. 3, p. 235.

10 Ibid.

11 Galeotti, n. 3, p. 10.

12 Rawls, n. 1, p. xlii.

13 There is in fact reason to question the empirical plausibility of the very idea of the self-sustainability of a morally stable system of political norms. As it has been persuasively argued, Rawls' notion of a stable political morality rests on an empirically unwarranted understanding of moral development-see Sterling Lynch (2009) 'The Fact of Diversity and Reasonable Pluralism', Journal of Moral Philosophy 6: 7093. (We could in fact note that Rawls' theory of justice revived normative political theory by following the fashion of its time and building on non-empirical foundations. While the Rawls' game-theoretic claims have largely been found lacking, the reliance on controversial, broadly Kohlbergian notions of moral development has received less scrutiny, despite the central role of the notion of stability in Rawls' later work.) There is no clear account in Rawls of how exactly just institutions can generate persistent support, and empirical studies of the transmission of political ideologies point towards a healthy pessimism on the ability of civil society or even deliberate citizenship-building programmes to deliver stability. To be sure, one may think that - ceteris paribus-moral support for a political morality will make it less likely that people will want to abandon it or shirk. But if stability in both senses is unlikely anyway, then arguments from stability are reduced to only providing pro tanto reasons with very limited purchase. Relatedly, just as an arrangement borne out of political expediency can evolve into a principled settlement, the opposite process is also possible, and it is at least an open question whether it is not just as likely, or at least not significantly less likely. Cf. Richard H. Dees (1999) 'Establishing Toleration', Political Theory 27: 667-693, an apt criticism of Rawls' conjectural story of the 
transition from modus vivendi to constitutional consensus and overlapping consensus. In addition to those empirical points, a more general and normative observation is in order. I simply think that it is possible to bite the bullet of arguments from stability, or even to deflect it back, as it were: liberal theory cannot wish away the sometimes unpalatable compromises that characterise the very nature of politics, and an adequate account of the moral foundations of tolerance should not be blind to the appeal of pragmatic justifications. Cf. Glen Newey (2001) After Politics. London: Palgrave Macmillan.

14 The distinction between viability, achievability and feasibility has been articulated by Erik $\mathrm{O}$. Wright (2007) 'Guidelines for Envisioning Real Utopias', Soundings 36: 26-39.

15 Rainer Forst (2003) Toleranz im Konflikt. Frankfurt a.M.: Suhrkamp, p36 shows how the very concept of tolerance implies the need to determine the limits of tolerance.

16 Objections from this family have a long pedigree: the argument originated with Samuel T. Coleridge (1969) [1818]. 'Section First on the Principles of Political Knowledge', in K. Coburn (ed.), The Collected Works of Samuel Taylor Coleridge, vol. 4/1. Princeton: Princeton University Press; a version of it can be found in Henry Sidgwick (1981) [1907] The Methods of Ethics. Cambridge: Hackett. Similar arguments have been proposed more recently by H.L.A. Hart, 'Rawls on Liberty and Its Priority', in N. Daniels (ed.) (1975) Reading Rawls pp 230-52. New York: Basic Books; Ronald Dworkin (1977) Taking Rights Seriously. Cambridge, MA: Harvard University Press; G.A. Cohen (1981) 'Freedom, Justice, and Capitalism', New Left Review 1: 3-16; and Charles Taylor (1985) 'What's Wrong with Negative Liberty?', in Pbilosophy and the Human Sciences, Philosophical Papers, vol. 2, pp211-29. Cambridge: Cambridge University Press. - Cf. Arthur Ripstein (2009) Force and Freedom. Cambridge: Cambridge University Press, pp32-33. Ripstein (ibid.) recently mounted a Kantian reply to these objections-I will discuss his position in section 4 below.

17 Stephen Darwall (1977) 'Two Kinds of Respect', Ethics 88: 36-49.

18 This notion has been insightfully problematised by Ian Carter (2011) 'Respect and the Basis of Equality', Ethics 121: 538-571.

19 Here one may object that appraisal respect for an aspect of X may warrant its tolerance despite an overall negative assessment of X ("Zoroastrians are despicable, but I tolerate them because of their great music"). Yet I would reply that, strictly speaking, that sort of consideration is not really a reason to tolerate $\mathrm{X}$, for if the appraisal-worthy feature could be maintained while $\mathrm{X}$ is eliminated then we would have no reason not to do so. And that rules out appraisal respect here, for proponents of respect-based tolerance seek a principled justification, rather than one dependent on practical contingencies.

20 Scanlon, n. 3. pp234-235.

21 Here one easily notices the similarities between this position and the moral theory developed in Thomas Scanlon (1998) What We Owe to Each Other. Cambridge, MA: Harvard University Press.

22 This problem is analogous to the puzzle of 'saving the greater number', a well-known problem for Kantian ethics. See John M. Taurek (1977) 'Should the Numbers Count?', Philosopby and Public Affairs 6: 293-316.

23 Scanlon, n. 3, p. 235. Compatibly with the argument I will put forward below, one may observe that this attitude might be unattainable (whatever that means, exactly) if we have to tolerate in the pure tolerance sense; but we can certainly tolerate racists as second best, given certain political circumstances.

24 Scanlon, n. 3, p. 235.

25 This runs parallel to many well-known arguments against Rawls' use of reasonableness in Political Liberalism, which I discuss in 3.2 below.

26 That is, of course, a version of the general criticism of neo-Kantian accounts of justice put forward by Michael Sandel (1998) Liberalism and the Limits of Justice. 2nd ed. Cambridge: Cambridge University Press, and others. As it has been widely argued, the general point retains some force even in light of Rawls' later distinction between the political and the comprehensive.

27 Galeotti, n. 3, p. 13.

28 I develop this objection in Enzo Rossi (2008), Liberal Legitimacy, PhD Thesis, Philosophy Departments, University of St Andrews..

29 Galeotti, n. 2, pp58-63. 
30 Ibid., pp59-60, my translation.

31 Williams, n. 3, p. 26. Interestingly, in her latest work on this subject Galeotti (n. 2) seems to be moving away from the phrase 'tolerance as recognition' and towards 'respect as recognition' — a terminological shift which may well signal an acknowledgment of the thorny issue of the limits of tolerance.

32 Ripstein, n. 15, p. 33.

33 For instance, Thomas Nagel puts it as follows: "Part of the problem is that liberals ask of everyone a certain restraint in calling for the use of state power to further specific, controversial moral or religious conceptions - but the results of that restraint appear with suspicious frequency to favour precisely the controversial moral conceptions that liberals usually hold". See (1987) 'Moral Conflict and Political Legitimacy', Philosophy and Public Affairs 16: 215-240, p216.

34 Williams, n. 3, p. 24.

35 Those two approaches are exemplified by Joseph Raz (1986) The Morality of Freedom. Oxford: Clarendon Press and John Gray (2000) Two Faces of Liberalism. Cambridge: Polity Press, respectively.

36 'Unprincipled' should be understood loosely here, as it is mainly meant as a response to Scanlon's idea of principled toleration. To be more precise, we could say that on both accounts toleration has non-intrinsic value.

37 However, one should not be too quick in accusing realism of stifling social criticism, as the former may well be a precondition of the latter. On this point see Raymond Geuss (2011) 'Realismus, Wunschdenken, Utopie', Deutsche Zeitschrift für Philosophie 58: 419-429.

38 Previous versions of this paper were presented at the RESPECT Workshop at the University of Copenhagen, at the Manchester Metropolitan University Workshops in Political Theory, and at a workshop on toleration at the University of Milan. I am indebted to all audiences for their comments, and especially to Anna Elisabetta Galeotti and Peter Jones. I should also thank Federico Zuolo and an anonymous referee for their written comments. The research informing the paper was supported by the European Commission, 7th Framework Program, Project RESPECT (GA no. 244549). 